\title{
El Hábeas Data, protección al derecho a la información y a la autodeterminación informativa
}

\author{
The Habeas Data, protection to the right of information and informational Self- \\ Determination \\ Rosalía Quiroz Papa de García \\ Universidad Nacional Mayor de San Marcos \\ Contacto: rquirozp@unmsm.edu.pe
}

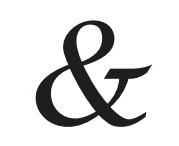

\section{Resumen}

La investigación describe y analiza el nivel de protección al derecho de acceso a la información y la protección de datos personales o autodeterminación informativa, a través de las jurisprudencias de Hábeas Data resueltas por el Tribunal Constitucional del Perú durante los últimos cinco años (2010-2014). Se identifica los lugares de mayor incidencia de este tipo de garantías, el tipo de demandantes y demandados, la materia de la demanda y el tipo de fallos emitidos por el Tribunal que dieron fin a las demandas de Hábeas Data.

Palabras clave: Acceso a la información. Derecho a la información. Autodeterminación informativa. Hábeas Data. Protección de datos personales.

\begin{abstract}
The research describes and analyses the level of protection of the right of access to information and protection of personal data or informational self-determination, through the jurisprudence of Habeas Data determined by the Constitutional Court of Peru during the last five years (2010-2014). It identifies the places of highest incidences of this type of guarantee, types of plaintiffs and defendants, the matter of demand and the type decisions issued by the Court that ended to the demands of Habeas Data.

Keywords: Access to information. Right to information. Informational self-determination. Habeas Data. Personal data protection.

Recibido: 13/8/16. Aceptado: 15/9/16
\end{abstract}


Rosalía Quiroz Papa de García

\section{Introducción}

El recurso de agravio constitucional denominado Hábeas Data, es una garantía que protege dos derechos fundamentales: el derecho a la información y la autodeterminación informativa o protección de datos personales; ambos, forman parte del ámbito de los derechos humanos, reconocidos y protegidos por los Tratados Internacionales y las Cartas Constitucionales de los diferentes países en los que impera el estado de derecho. No obstante, el avance de las nuevas tecnologías de la información y las comunicaciones, propias de la sociedad de la información en la que vivimos, las han puesto en riesgo, tal como lo advierte Flores (2011): "Es así que el surgimiento de la informática y su impacto en el ámbito jurídico, ha dado lugar a la figura de la "libertad informática" o “autodeterminación informativa”, considerados como derechos de tercera generación, y que sean protegidos a través de normas constitucionales y normas específicas “(p.58).

\section{El acceso a la información como derecho humano}

El derecho de acceso a la información, es un derecho humano de tercera generación. Como lo manifiesta Salazar (2006), quien cita a Ekmekdjian y Pizzolo (1995):

\footnotetext{
Luego del logro jurídico sobre las libertades individuales y los derechos sociales se ha arribado a la tercera generación de los nuevos "derechos fundamentales donde figuran -entre otros- el derecho a la mejor calidad de vida, el derecho a la defensa del ecosistema, el derecho de los pueblos al desarrollo, al progreso, a la explotación de los propios recursos, a la paz, a la autodeterminación, a la integridad regional. También está incluido el derecho a la protección de datos o libertad informática”. (p. 25)
}

Es la facultad de las personas de solicitar y acceder a la información pública que se encuentra en todas las entidades del Estado y las empresas privadas que presten servicios al público, Asimismo, se entiende por información 
pública, al conjunto de datos almacenados o creados por los diferentes organismos gubernamentales y que precisamente, por tener carácter público pertenece a todos los miembros de la sociedad, y que pueden ser solicitados sin expresión de causa o explicación alguna, y con solo el costo de su reproducción, tal como señala el Tribunal Constitucional en afinada síntesis y clara advertencia: "El derecho de acceso a la información pública resultaría siendo ilusorio si el costo que se exige por la reproducción de la información representa un monto desproporcionado o ausente de un fundamento real. Ello ocasionaría el efecto práctico de una denegatoria de información y, con ello, lesivo de este derecho fundamental”. (STC N. ${ }^{\circ}$ 1912-2007-PHD/TC, fundamento 4).

Cuando utilizamos la palabra acceso podemos referirnos a muchas cosas. La polisemia de la palabra exige que se acompañe de otras que vengan a matizar su significado... Como derecho, son muchas las referencias: acceso a la cultura, a la educación, al autogobierno; el derecho de acceso a los medios de titularidad pública, acceso a Internet y a la banda ancha, a la jurisdicción, a las prestaciones de la seguridad social, a los servicios sociales o los derechos de acceso a los servicios públicos y a una buena Administración... (Sánchez de Diego, 2008, p. 7).

Los principios sobre los que gira el acceso a la información, son esencialmente los de participación, fiscalización, transparencia y el de publicidad de los actos gubernamentales, saber qué hacen los funcionarios públicos en la función que se les ha encomendado, como un medio de transparentar y fortalecer la democracia, dejando de lado la cultura del secreto tan arraigada en la sociedad.

Este derecho de acceso a la información pública adquiere una dimensión importantísima cuando se le observa a partir de las connotaciones tecnológicas y sociales de la asíllamada "sociedad de la información”. En efecto, en esta sociedad, donde la información ha adquirido un valor económico en proporciones verdaderamente insospechadas, se están gestando las condiciones para una sociedad más abierta y transparente. La "sociedad de la información” no sólo ha 
transformado los conceptos sociales de distancia y tiempo, sino que también ha influido decididamente en el concepto de "opinión pública” y "participación ciudadana”, la cual ahora puede formarse con total prescindencia de las condiciones existentes en un determinado país y coyuntura temporal. (Estrada, 2004, p. 170).

La base legal se encuentra en las siguientes normas:

Declaración Universal de los Derechos Humanos (1948)

Artículo 19.- "Todo individuo tiene derecho a la libertad de opinión y expresión: este derecho incluye el de no ser molestado a causa de sus opiniones, el de investigar y recibir informaciones y opiniones, y el de difundirlas sin limitación de fronteras, por cualquier medio de expresión”.

Constitución Política del Perú de 1973

Artículo 2. Toda persona tiene derecho:

5.- A solicitar sin expresión de causa la información que requiera y a recibirla de cualquier entidad pública, en el plazo legal, con el costo que suponga el pedido. Se exceptúan las informaciones que afectan la intimidad personal y las que expresamente se excluyan por ley o por razones de seguridad nacional. (...)

Este derecho alcanza a todas las personas naturales o jurídicas que soliciten información, en tanto que las entidades obligadas a entregar información son todas las dependencias del Estado en sus tres niveles, Gobierno Central, Gobierno Regional y Gobierno Local. Asimismo, las empresas privadas que gestionen servicios públicos tienen la obligación de informar sobre las características de sus servicios; por ejemplo, los colegios profesionales que manejan información de conocimiento público, los notarios, que no son funcionarios del Estado; pero, cumplen una función pública, los colegios y universidades privadas, etc. "El primer principio es la absoluta libertad para que cualquier ciudadano y el Estado puedan recolectar cualquier dato que sea de carácter no personal, fáctico, histórico, científico...”(Viera, 1997, p. 198).

El Tribunal Constitucional a través de un importante número de jurisprudencias ha establecido con claridad y amplitud los alcances sobre el ejercicio de este derecho, así como las características que la información que se 
otorga debe tener.

Sobre el contenido de la información a entregarse, este debe ser "oportuna, incondicional y completa" (STC 04885-2007-HD), que debe ser entregada en "términos mínima o elementalmente razonables, lo que supone que ésta debe ser cierta, completa, clara y, además, actual" (STC 00007-2003-AI). Considera además que se afecta el derecho de acceso a la información "cuando la información que se proporcione es fragmentaria, desactualizada, incompleta, imprecisa, falsa, no oportuna o errada" (STC 01797-2002-HD). (Sosa, 2012, p. 1).

\section{Derecho a la privacidad y la autodeterminación informativa}

El término privacidad se deriva de lo privado. "Dícese de lo que tiene carácter particular (...). Personal, confidencial. Todo lo que concierne al llamado derecho privado" (Flores, 1987, p. 435). Lo conforman aquellas acciones propias, particulares y personales de los individuos, correspondiéndole solo al titular decidir sobre ellos. Constituye uno de los valores más importantes de respeto al ser humano.

La privacidad, término castellanizado que proviene de la palabra anglosajona "privacy", constituye el conjunto de actividades que el hombre desarrolla en la colectividad y en grupos reducidos pero que desea preservar del conocimiento ajeno y, de su tratamiento informatizado, porque si bien podrían parecer informaciones inofensivas e intrascendentes para la persona afectada, la utilización y tratamiento informático de las mismas puede transformarla en comprometedoras para el libre desarrollo de la personalidad del individuo (Marecos, 2011, p.53).

El derecho a la privacidad se define como la libertad, la facultad que toda persona tiene de desenvolverse en el ámbito social, familiar o personal, de acuerdo a sus propios patrones de conducta, hábitos o costumbres. Por lo que nadie debe inmiscuirse en ella, si no es con su autorización. El derecho a decidir en qué medida compartirá con los demás sus pensamientos, sus sentimientos y los hechos de su vida personal, comprende los aspectos muy particulares de la identidad individual, la voz, la imagen, la edad, la nacionalidad, la salud, los 
hábitos sexuales, las ideas religiosas, políticas, filosóficas, la situación patrimonial, financiera; en suma, sus datos estrictamente personales. Por otro lado, la imparable revolución de las TIC ha dado lugar a que este derecho se regule jurídicamente a fin de proteger la libertad y la intimidad, amenazados por el acopio de datos y la existencia de sofisticados sistemas de registros automatizados en entidades públicas y privadas.

La influencia de los avances tecnológicos es sin duda un elemento determinante para la protección de la privacidad de todas las personas, que plantea diariamente nuevos desafíos, en los cuales es necesario lograr un equilibrio entre la tecnología y la protección de los datos personales, con la ayuda de herramientas jurídicas y tecnológicas. (Viega y Baladán, 2014, p. 180).

El bien tutelado es la reserva de la intimidad, que no haya injerencia por parte del Estado ni de particulares; se protege a través de la acción judicial de Hábeas Data. La base legal se encuentra en la Declaración Universal de los Derechos Humanos (1948).

Artículo 12.- Nadie será objeto de injerencias arbitrarias en su vida privada, su familia, su domicilio o su correspondencia, ni de ataques a su honra o a su reputación. Toda persona tiene derecho a la protección de la ley contra tales injerencias o ataques.

Y, en la Constitución Política del Perú de 1993.

Artículo 2. Toda persona tiene derecho:

Inc. 6. A que los servicios informáticos, computarizados o no, públicos o privados, no suministren informaciones que afecten la intimidad personal y familiar.

Inc. 7. Al honor y a la buena reputación, a la intimidad personal y familiar así como a la voz y a la imagen propias. Toda persona afectada por afirmaciones inexactas o agraviadas en cualquier medio de comunicación social tiene derecho a que éste se rectifique en forma gratuita, inmediata y proporcional, sin perjuicio de las responsabilidades de ley.

\section{Límite entre el derecho a la información y el derecho a la privacidad}

Cabe precisar que, si bien es cierto que el derecho a la información forma 
parte de los derechos fundamentales de tercera generación, cuya base es el principio de solidaridad, su límite es el derecho a la privacidad e intimidad de las personas. "...por ser derechos subjetivos, no son derechos absolutos que pueden ejercitarse sin ninguna limitación” (Pauner, 2014, p. 97). Nos encontramos así frente a dos derechos humanos aparentemente en pugna; por un lado, el derecho a la información, que constituye un elemento esencial para el desarrollo de la persona y de la sociedad; y por el otro, el derecho a la privacidad de todo ser humano que merece respeto y garantía de mantener su propio espacio de privacidad e intimidad libre de injerencias; particularmente, frente al abuso que pudiera cometer la informática en el acceso, distribución y manipulación de datos personales, por las enormes posibilidades de almacenar, procesar y transmitir una ilimitada cantidad de información, que podría causarle daño. “... como internet, donde la información circula por canales no protegidos, encriptados, que a su vez, generan grandes y complejos problemas de seguridad y confidencialidad" (Flores, 2011, p. 58). Esta realidad exige crear una serie de mecanismos preventivos y de control, que limiten, regulen y sancionen el accionar de las entidades públicas y privadas cuando tengan relación directa con el tratamiento de datos e información de índole personal, buscando un equilibrio entre estos dos derechos.

\section{Autodeterminación informativa}

Otro de los derechos fundamentales que se desprende del derecho a la privacidad, y que tiene relación directa con el Hábeas Data es la autodeterminación informativa, que es un derecho de tercera generación, cuya característica esencial es la solidaridad, ya que para su real garantía exige la acción mutua, tanto de la persona, el Estado y las entidades públicas y privadas. "Encontramos en la solidaridad la razón de ser de los derechos de tercera generación, como en su momento lo fue la libertad y la igualdad para los derechos de primera y segunda generación respectivamente" (Marecos, 2011, p.50). 
La justicia alemana lo denominó por primera vez como la "autodeterminación informativa", dicho principio fue enunciado en una célebre sentencia del Tribunal Constitucional alemán de Karslruhe el 15 de diciembre de $1983 .$. La sentencia sostuvo lo siguiente: que dicho derecho supone la facultad del individuo de disponer y relevar datos referentes a su vida privada, en todas las fases de elaboración y uso de datos, o sea, su acumulación, su transmisión, su modificación y su cancelación (Pulgar, 2006, p. 96).

Es el derecho que tiene toda persona de acceder y controlar la información personal registrada en bancos de datos públicos o privados, es el único que ejerce las facultades de: a) Solicitar la corrección, rectificación, actualización o modificación de datos inexactos. b) Solicitar la cancelación de datos obsoletos, inapropiados o irrelevantes. c) Facultad de solicitar la cancelación de datos personales obtenidos por procedimientos ilegales. c) Facultad de exigir que se adopten medidas suficientes para evitar la transmisión de datos a personas o entidades no autorizadas.

Como tal, faculta a los individuos decidir qué datos son los que pueden o no ser conocidos, autorización que debe ser expresa, porque es ella quien controla la información o los datos que se refieren a su persona, que no es más que la forma de preservar su privacidad, frente al peligro de las bases de datos y al uso de las nuevas tecnologías y sus potentes herramientas de acopio y procesamiento, que ha generado nuevas modalidades de amenaza y agresión a los derechos y libertades, tipificados como delitos informáticos. Por los que toda persona debe contar con efectivas garantías legales que protejan el tratamiento de sus datos personales. Es así que, "Las nuevas condiciones de ejercicio de los derechos humanos han determinado una nueva forma de ser ciudadano en el Estado de Derecho de las sociedades tecnológicas (...) (Marecos, 2010, p. 52). 
El Hábeas Data, protección al derecho a la información y a la autodeterminación informativa

\section{Datos sensibles}

Se denomina así a todos aquellos datos personales estrictamente reservados que caracterizan la individualidad y la personalidad de los sujetos y, como tal, forman parte de su privacidad. Lo conforman: el origen étnico, las opiniones políticas, convicciones religiosas, filosóficas o morales, afiliación sindical e información referente a la salud o la orientación sexual. Si éstos han sido registrados en el cumplimiento de determinados fines, para la investigación, censos estadísticos, estudios científicos, para fines oficiales del Estado, solucionar problemas de salud, etc. deben ser con su consentimiento expreso y merecen una especial protección jurídica, tal como lo manda la ley, para evitar daños y perjuicios a la persona, como puede ser la discriminación, lo advierte Velezmoro (2006):

... de un tiempo a esta parte se ha llamado la atención sobre las posibilidades de que el tratamiento automatizado de datos pueda ser perjudicial para la persona; de hecho, la facilidad de la recolección, tratamiento y entrecruzamiento de datos es notoria con el desarrollo de las tecnologías de la información y comunicación. (p.159).

Es así que los datos sensibles solo pueden ser acopiados cuando existan o se justifiquen razones de interés general, por mandato judicial, para fines estadísticos o científicos. En caso de registrarlos a través de medios digitales, las entidades públicas y privadas están obligadas de contar con políticas de privacidad, plasmadas en documentos que señalen con claridad los mecanismos de protección en el manejo de la información de sus clientes, usuarios, proveedores y empleados.

\section{Hábeas Data}

El término "hábeas data”, se deriva de los vocablos “conserva”, "trae”, “encuentra”. Compuesto a su vez, de dos términos: Data.- Acusativo plural de datum, término en inglés, que como sustantivo plural significa "información o datos". Hábeas.- Segunda persona del presente subjuntivo del latín habeo 
(habere), cuyo significado es "téngase en posesión" “exhibir", "tomar", "traer", "que se tenga, traiga o exhiba o presente los datos".

La locución "hábeas data" se forma con habeas (del latín habeo, habere), que significa tener, exhibir, tomar, traer, etc.; adosándole el vocablo data, respecto del cual existe alguna disputa léxica, pues mientras algunos afirman que se refiere al acusativo neutro plural de datum: lo que se da, datos-también del latín-otros sostienen que la palabra data proviene del inglés, con el significado de información o datos”. (Castillo, s.a., p. 1008).

A nivel de Latinoamérica, los primeros antecedentes de esta figura, se encuentra en la Constitución de Brasil (1988), que fue la primera en usar el término de "Hábeas Data".

En el ámbito latinoamericano, fue la constitución brasileña de 1988, en su Art. $5^{\circ}$, Inc. LXXII, la primera en abordar estos temas, pero sobre todo, también la primera en "bautizar" constitucionalmente al instituto del Hábeas Data. Dicha norma dispone que: "Se concederá Hábeas Data: a) para asegurar el conocimiento de informaciones relativas a la persona de quien lo pide, que consten en registros o bancos de datos de entidades gubernamentales o de carácter público; b) para la rectificación de datos, cuando se dé prefiera hacerlo en proceso reservado judicial o administrativo (Eguiguren, 1997, p. 295).

A nivel mundial, destacan tres grandes modelos de protección de datos: El modelo de EE.UU; el modelo Europeo y el modelo Latinoamericano (Villegas, 2012, p. 128). En el Perú, la figura del Hábeas Data se incorporó en la Constitución de 1993 como una garantía constitucional.

Artículo $200^{\circ}$.- Acciones de Garantía Constitucional. La Acción de Hábeas Data, que procede contra el hecho u omisión, por parte de cualquier autoridad, funcionario o persona, que vulnera o amenaza los derechos a que se refiere el artículo $2^{\circ}$, incisos 5 y 6 de la Constitución. Incisos 2) y 3) modificados por el Artículo $1^{\circ}$ de la Ley $N^{\circ} 26470$, publicada el 12-06-1995.

Varios años después (2011), se promulga la Ley de Protección de Datos 
Personales, que protege los datos “...contenidos en bancos de datos personales de administración pública y de administración privada, cuyo tratamiento se realiza en el territorio nacional. Son objeto de especial protección los datos sensibles" (Ley $\mathrm{N}^{\circ} 29733$, Artículo 3). Su finalidad es tutelar el derecho al honor y a la intimidad de las personas, garantizando el acceso a sus datos, siempre que éstos se encuentren en una base de datos manual, computarizada, electrónica o magnética. Y si amenazaran su privacidad, los afectados pueden solicitar la supresión, rectificación, confidencialidad o actualización de sus datos a través de un proceso judicial de Hábeas Data.

Chiriboga (2001) señala:

El hábeas data es una garantía constitucional, con objetivos muy precisos, que busca que el accionante sepa:

1. Por qué motivos legales el poseedor de la información llegó a obtenerla;

2. Desde cuando tiene la información;

3. Qué uso ha dado a esa información y qué hará con ella en el futuro;

4. Conocer a qué personas, naturales o jurídicas, el poseedor de la información les hizo llegar dicha información. Por qué motivo, con qué propósito y la fecha en la que circuló la información;

5. Qué tecnologías usa para almacenar la información;

6. Qué seguridades ofrece el tenedor de la información para precautelar que la misma no sea usada indebidamente;

7. Qué información se tiene respecto a determinada persona y para qué se almacena;

8. Si la información es actualizada y correcta y, de no serlo, solicitar y obtener su actualización o rectificación; (pp.68-

69).

Por tanto, este recurso de agravio constitucional es una garantía, un proceso, un instrumento que posibilita la defensa del acceso a la información y la autodeterminación informativa, esta garantía de naturaleza procesal, permite 
que se efectivicen dos derechos fundamentales:

a. El acceso a la información, contenida en los archivos y registros de todas las entidades del Estado y los privados, siempre que cumplan funciones públicas.

b. Defender la autodeterminación informativa, accediendo a los archivos para corregirlos, rectificarlos, actualizarlos, suprimirlos o mantenerlos en reserva, para así proteger la libertad personal, la privacidad y el honor. Como tal, su finalidad es tutelar el manejo de sus datos personales, que pudieran ser falsas, tergiversadas, desactualizadas, incompletas, etc. afectando la privacidad e intimidad individual.

Bien lo enfatiza Zambrano (2004):

El Hábeas Data tiene por finalidad impedir que se conozca la información contenida en los bancos de datos respecto de la persona titular del derecho que interpone la acción, cuando dicha información esté referida a aspectos de su personalidad que están directamente vinculados con su intimidad y privacidad, no pudiendo entonces encontrarse a la libre disposición del público o ser utilizados en su perjuicio por órganos públicos o entes privados, sin derecho alguno que sustente dicho uso. Se trata, particularmente de información relativa a la filiación política, a las creencias religiosas, la militancia gremial, el desempeño en el ámbito laboral, o académico, entre muchos otros objetivos de protección. (p. 185)

Por su parte, Pérez sostiene (1990):

Al cotejar el hábeas corpus y el hábeas data, se comprueba una inicial coincidencia en lo referente a su naturaleza jurídica. En ambos casos no se trata de derechos fundamentales, estricto sensu, sino de instrumentos o garantías procesales de defensa de los derechos a la libertad personal, en el caso del hábeas corpus, y de la libertad informática en lo concerniente al hábeas data” (p.157).

\section{Protección de datos personales}

“Datos personales. Toda información sobre una persona natural que la identifica o la hace identificable a través de medios que pueden ser razonablemente utilizados” (Ley $\mathrm{N}^{\circ} 29733$, Artículo 2. 4). La protección de datos 
personales está íntimamente relacionada con la autodeterminación informativa, la privacidad y con el proceso de agravio constitucional de Hábeas Data. Su reconocimiento se encuentra en la Declaración Universal de los Derechos Humanos (1948). Las leyes sobre la materia en esta parte de América Latina, han sido influenciadas por el Modelo Europeo, particularmente por la directiva europea 95/46 (Vásquez, 2012, p. 33). Uno de los últimos países en aprobar la Ley de Protección de Datos Personales, Ley Nº 29733 (2011), ha sido el Perú, dos años después se aprobó el Reglamento que entró plenamente en vigencia el año 2015. Es de notar que en la sociedad y en casi todas las organizaciones públicas y privadas, es aún incipiente la cultura de protección de datos personales, la ciudadanía desconoce que forma parte de sus derechos fundamentales y que tiene la titularidad sobre ellos, cuyo registro, manipulación y transferencia sin su consentimiento, en particular con las nuevas tecnologías de la información, puede ocasionar daños y perjuicios con graves repercusiones en su vida personal, social o profesional. "Cuanto más avanza la sociedad de la información, más se sabe, cada día, acerca de nosotros” (Corte Suprema de Justicia, 2010, p. 15).

\begin{abstract}
Como se evidencia la protección de datos no es de hoy, esta ha sido de gran importancia en la sociedad postindustrial, ya que para cualquier actividad, sea en la realidad virtual o en la realidad tangible, permanentemente se están brindando datos personales. Hoy en día se necesita cantidad de datos para abrir una cuenta de banco, para una rifa, para pagar una factura o para registrarse en una cuenta de una red social, por lo tanto toda esta información que se entrega es reflejo de quienes somos, es reflejo de la personalidad de cada uno, y debe ser protegida, resguardada (Agencia Española de protección de datos, p. $5)$.
\end{abstract}

El contenido de los datos personales lo conforma todos aquellos que lo identifique, del cual se obtiene un perfil de la persona a través del origen étnico, nombre, sexo, domicilio, nacionalidad, profesión, estado civil, créditos, situación crediticia, enfermedades, orientación política, religión, filosofía, etc. 
Son los antecedentes que permiten conocer a un individuo desde diversos ámbitos. "Cuanto más avanza la sociedad de la información, más se sabe, cada día, acerca de nosotros" (Corte Suprema de Justicia, 2010, p. 15).

En la vida diaria y para un sinnúmero de actividades, se interactúa con diversas clases de registros de datos, las mismas que son registradas para un sinnúmero de finalidades. Chanamé (2003) cita a Falcón (1996), quien los tipifica: Registros personales. Registros comerciales. Registros impositivos. Registros de propiedad. Registros políticos. Registros sanitarios. Registros de información y de simple registración. Registros públicos, registros semipúblicos, registros privados, registros secretos. (pp. 127-128). Asimismo, la siguiente Tabla muestra una extensa tipología de datos personales que pueden ser objeto de registro, tanto por la administración pública y privada.

\begin{tabular}{|c|l|}
\hline \multicolumn{2}{|c|}{ Datos personales } \\
\hline $\begin{array}{c}\text { Datos de } \\
\text { identificación }\end{array}$ & $\begin{array}{l}\text { nombre, apellido, domicilio, teléfono, PIN, correo electrónico, firma, DNI, } \\
\text { CUIT/L, fecha de nacimiento, edad, nacionalidad, estado civil, sexo, imagen, } \\
\text { dirección de IP, etc. }\end{array}$ \\
\hline Datos laborales & $\begin{array}{l}\text { puesto, empleador, domicilio, correo electróni co institucional, teléfono del } \\
\text { trabajo, legajo, nómina, sanciones, licencias, seguridad social, aportes, historial } \\
\text { en la empresa }\end{array}$ \\
\hline $\begin{array}{c}\text { Datos } \\
\text { patrimoniales }\end{array}$ & $\begin{array}{l}\text { información fiscal, historial crediticio, cuentas bancarias, ingresos y egresos, } \\
\text { información de consumos, situación de solvencia, etc. }\end{array}$ \\
\hline $\begin{array}{c}\text { Datos } \\
\text { académicos }\end{array}$ & $\begin{array}{l}\text { curriculum vitae, trayectoria educativa, títulos, matriculas habilitantes, } \\
\text { certificados, condición de alumno, calificaciones, etc. }\end{array}$ \\
\hline $\begin{array}{c}\text { Datos } \\
\text { ideológicos }\end{array}$ & $\begin{array}{l}\text { creencias religiosas, afiliación política, sindical, pertenencia a organizaciones de } \\
\text { la sociedad civil, asociaciones religiosas, etc. }\end{array}$ \\
\hline $\begin{array}{c}\text { Datos de salud } \\
\text { laracterísticas } \\
\text { personales y } \\
\text { físicas }\end{array}$ & $\begin{array}{l}\text { estado de salud, historial clínico, enfermedades, información relacionada con } \\
\text { cuestiones de carácter psicológico, psiquiátrico, régimen de licencias, etc }\end{array}$ \\
\hline $\begin{array}{l}\text { tipo de sangre, ADN, huella digital, altura, peso, discapacidades, color de piel, } \\
\text { iris yabellos, señales particulares, etc. origen étnico y racial, orientación sexual, }\end{array}$ \\
\hline
\end{tabular}

Fuente: http://www.habeasdat.com/faq.html

\section{Material y métodos}

La investigación es de tipo aplicada, el método empleado es el jurídicodescriptivo y documental. Para mayor fiabilidad de los datos, se trabajó en base a la revisión bibliográfica y documental de las jurisprudencias del Tribunal Constitucional sobre el proceso de Hábeas Data, los mismos que abarcan el ámbito temporal de cinco años (2010-2014).

Población y muestra.- Para efectos de esta investigación, la población estuvo 
conformada por todas las jurisprudencias que sobre Hábeas Data se encuentran publicadas en el Portal del Tribunal Constitucional desde el año 1996, que suma un total de 634 en 18 años. .

Tabla $N^{\circ} 2$ Total de expedientes sobre Hábeas Data (1996-2014)

\begin{tabular}{|c|c|c|c|c|c|}
\hline $\begin{array}{c}\text { Años } \\
(\mathbf{1 9 9 6 - 2 0 0 6 )}\end{array}$ & $\begin{array}{c}\text { Exp. } \\
\text { Ingresados }\end{array}$ & $\begin{array}{c}\text { Resoluciones } \\
\text { publicadas }\end{array}$ & $\begin{array}{c}\text { Años } \\
\mathbf{( 2 0 0 7 - 2 0 1 4 )}\end{array}$ & $\begin{array}{c}\text { Exp. } \\
\text { Ingresados }\end{array}$ & $\begin{array}{c}\text { Resoluciones } \\
\text { publicadas }\end{array}$ \\
\hline 1996 & 5 & $\mathrm{O}$ & 2005 & 13 & 9 \\
\hline 1997 & 1 & 1 & 2006 & 77 & 9 \\
\hline 1998 & 5 & 3 & 2007 & 75 & 81 \\
\hline 1999 & 2 & 3 & 2008 & 42 & 72 \\
\hline 2000 & 5 & 4 & 2009 & 73 & 43 \\
\hline 2001 & 2 & 3 & 2010 & 51 & 106 \\
\hline 2002 & 7 & 4 & 2011 & 63 & 53 \\
\hline 2003 & 9 & 7 & 2012 & 72 & 36 \\
\hline 2004 & 11 & 10 & 2013 & 282 & 91 \\
\hline & ---- & ----- & 2014 & 195 & 99 \\
\hline Total & 47 & 35 & - & 943 & 599 \\
\hline
\end{tabular}

Fuente: http://www.tc.gob.pe/portal/tc_estadisticas_gen.php

De todas las resoluciones publicadas, se tomó como muestra no probabilística 207 jurisprudencias de los últimos cinco años (2010-2014). El criterio de selección fue intencional, descartando aquellas resoluciones referidas a un mismo tipo de materia y tramitadas ante la misma institución, caso ONP, Ministerio de Trabajo, Municipalidades, etc.

Gráfico N 1 Muestra de jurisprudencias sobre Hábeas Data (2010-2014)

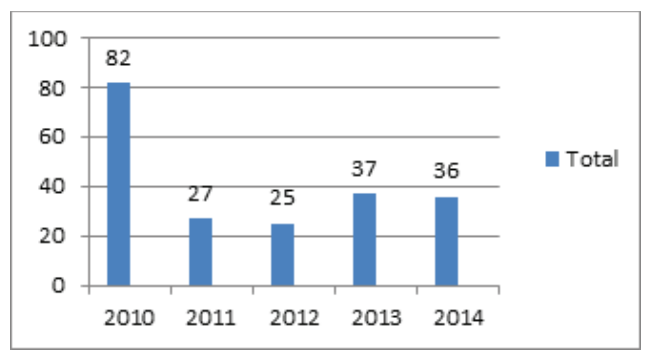

Instrumentos de recolección de datos -- Se diseñó una matríz de datos de doble entrada para acopiar la información que permitiera conocer el contenido de las 
jurisprudencias. Luego de ubicar e identificar los expedientes sobre la materia de interés, se procedió a resumirlos en base a la tabla de variables establecida previamente, para finalmente, a través de un estudio analítico e interpretativo cuantificar en una tabla de frecuencias los hallazgos en lo que respecta a cada uno de los indicadores objeto de la investigación.

Variables e indicadores de estudio.- Estos se resumen como sigue.

Tabla № 3 Variables e indicadores

\begin{tabular}{|c|c|c|}
\hline & Variables & Indicadores \\
\hline 1 & Lugar de la demanda de Hábeas Data & \begin{tabular}{|ll} 
a. & Lima \\
b. & Otros departamentos
\end{tabular} \\
\hline 2 & Demandante & $\begin{array}{|ll|}\text { a. } & \text { Persona natural } \\
\text { b. } & \text { Persona jurídica } \\
\end{array}$ \\
\hline 3 & Demandado & $\begin{array}{ll}\text { a. } & \text { Entidades públicas } \\
\text { b. } & \text { Entidades privadas } \\
\end{array}$ \\
\hline 4 & Materia de la demanda de Hábeas Data & $\begin{array}{|ll|}\text { a. } & \text { Acceso a la información } \\
\text { b. } & \text { Autodeterminación informativa } \\
\end{array}$ \\
\hline 5 & Fallo del Tribunal & $\begin{array}{ll}\text { a. } & \text { Fundada } \\
\text { b. } & \text { Infundada } \\
\text { c. } & \text { Improcedente } \\
\text { d. } & \text { Revocado } \\
\text { e. } & \text { Nulo }\end{array}$ \\
\hline
\end{tabular}

En el Anexo $\mathrm{N}^{\circ} 1$, se incluye el número de expediente con los que se identifica a cada una de las jurisprudencias analizadas.

\section{Resultados}

Tomando como base el marco metodológico expuesto, así como la tabla de variables e indicadores, a continuación se describe, analiza e interpreta, la información obtenida de la revisión de las jurisprudencias del Tribunal Constitucional (2010-2014).

\section{Lugar de la demanda de Hábeas Data}

Esta variable se refiere a la jurisdicción territorial donde se presentaron las demandas de Hábeas Data. Los siguientes datos muestran que casi la mitad (48\%) de las demandas se iniciaron en los Juzgados Civiles de Lima Metropolitana (100 casos), lo cual indica que, por la densidad poblacional de la capital, es explicable este resultado. Mientras que un poco más de la mitad (107 casos, $52 \%$ ) de las demandas, corresponden a las demás ciudades del país. Los departamentos en los que se presentaron mayor número de demandas fueron: Ica, Arequipa y Lambayeque. Esto preocupa, por cuanto es una limitación al 
ejercicio del derecho de acceso a la información para los habitantes del interior del país; más aún, muestra un alto grado de desconocimiento respecto a los mecanismos de protección de datos personales (autodeterminación informativa), lo que exige mayor difusión, a fin que se efectivice la real protección a estos derechos.

Tabla $\mathrm{N}^{\circ} 4$ Lugar de la demanda

\begin{tabular}{|l|c|c|c|c|c|c|c|}
\hline \multicolumn{1}{|c|}{ Lugar de la demanda } & $\mathbf{2 0 1 0}$ & $\mathbf{2 0 1 1}$ & $\mathbf{2 0 1 2}$ & $\mathbf{2 0 1 3}$ & $\mathbf{2 0 1 4}$ & Total & $\%$ \\
\hline Lima metropolitana & 46 & 14 & 10 & 23 & 7 & 100 & $48 \%$ \\
\hline $\begin{array}{l}\text { Otras ciudades y departamentos fuera de } \\
\text { Lima (Cañete, Huaura, Ica, Cuzco, } \\
\text { Lambayeque, Piura, La Libertad, Arequipa, } \\
\text { Junín, Ayacucho, Ucayali, Loreto) }\end{array}$ & 36 & 13 & 15 & 14 & 29 & 107 & $52 \%$ \\
\hline \multicolumn{1}{|c|}{ Total } & 82 & 27 & 25 & 37 & 36 & 207 & $100 \%$ \\
\hline
\end{tabular}

Gráfico N 2 Comparativo de casos entre Lima y otras ciudades
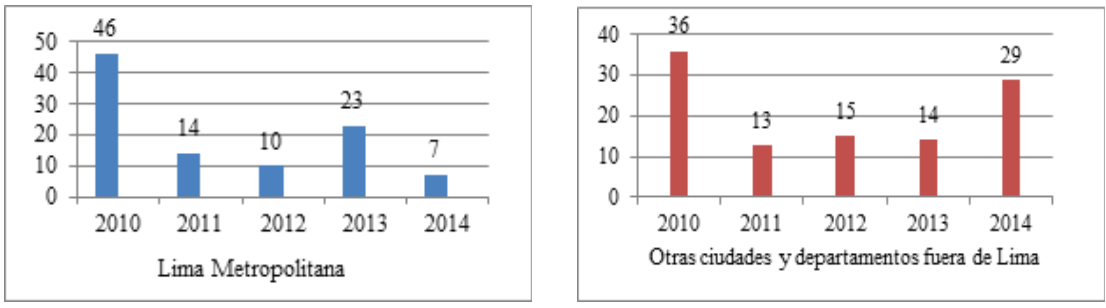

\section{Demandantes}

Los demandantes son las personas naturales o jurídicas que entablan una acción judicial, en este caso, el Hábeas Data. Los resultados del siguiente Gráfico indican que un alto porcentaje de las demandas (93\%) fueron presentadas por personas naturales, quienes iniciaron el proceso al ver afectados sus derechos, y solo un reducido 7\%, por personas jurídicas, quienes hicieron uso del proceso constitucional de Hábeas Data. Esto se explica por el mayor interés o necesidad de los ciudadanos de acceder a la información pública, y desconocimiento respecto a la protección de datos o autodeterminación informativa. 
Gráfico ํㅜ 3 Demandantes

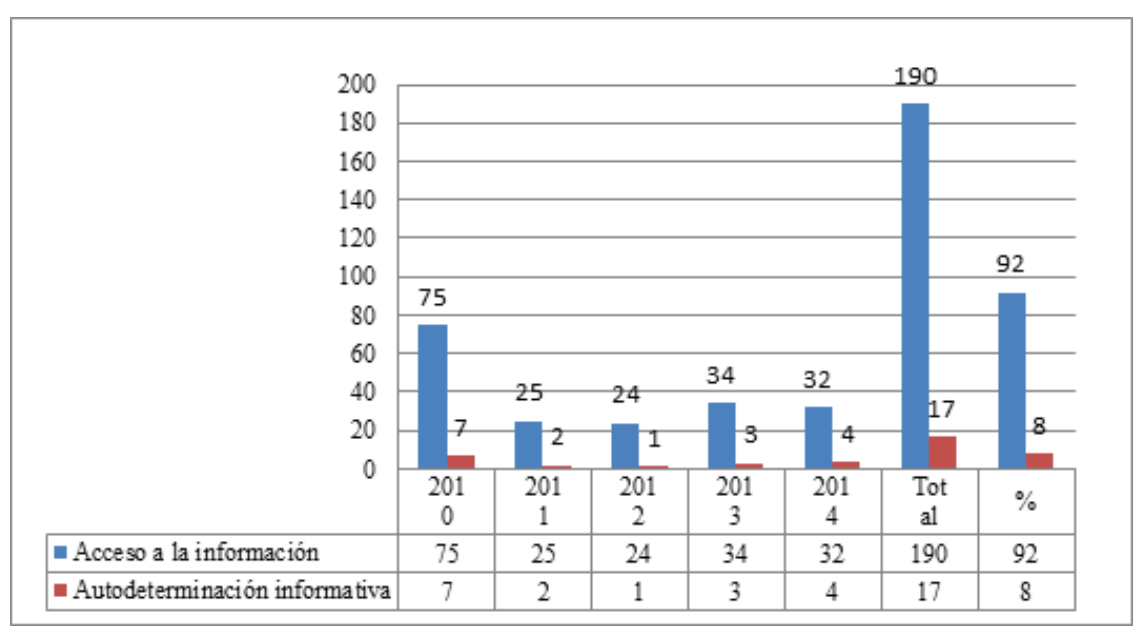

Demandados

Lo conforman las personas naturales o jurídicas contra quienes se inicia un proceso judicial. Los datos que se adjunta en la siguiente Tabla, muestran que las entidades con mayor número de demandas fueron los organismos públicas; entre ellas, los ministerios (33\%), seguido de las municipalidades (15\%). Esto se explica, porque a nivel del Gobierno Central, es el Poder Ejecutivo quien aglutina a la mayoría de organismos descentralizados, y a nivel de Gobiernos Locales, son las municipalidades representadas por sus alcaldes, los que ejercen función pública. Y, sobre las demandas presentadas contra las entidades privadas, estos representan escasamente el 8\%, lo cual muestra desconocimiento de la población de ejercer su derecho de acceso a la información o la autodeterminación informativa, también, contra entidades privadas que prestan servicios públicos. 
Tabla $\mathrm{N}^{\circ} 5$ Tipo de entidades demandadas

\begin{tabular}{|c|c|c|c|c|c|c|c|}
\hline Entidades demandadas & 2010 & 2011 & 2012 & 2013 & 2014 & Total & $\%$ \\
\hline \multicolumn{8}{|c|}{ Entidades públicas } \\
\hline Municipalidades & 12 & 4 & 3 & 1 & 10 & 30 & 15 \\
\hline Gobierno Regional & 1 & & & & & 1 & 0.5 \\
\hline Ministerios & 26 & 8 & 7 & 22 & 5 & 68 & 33 \\
\hline Ministerio Público & 4 & 2 & 2 & 4 & 4 & 16 & 8 \\
\hline Poder Judicial & 11 & 3 & 4 & 0 & 1 & 19 & 9 \\
\hline ONP & 2 & 1 & 1 & 1 & 1 & 6 & 3 \\
\hline Banco de la Nación & 2 & 0 & 0 & 0 & 1 & 3 & 1 \\
\hline SUNARP & 1 & 1 & 0 & 0 & 0 & 2 & 1 \\
\hline Universidad pública & 1 & 0 & 1 & 1 & 1 & 4 & 2 \\
\hline \begin{tabular}{|l} 
Sistema Electoral \\
(Reniec y Onpe)
\end{tabular} & 0 & 0 & 1 & 0 & 2 & 3 & 1 \\
\hline Total parcial & 60 & 19 & 18 & 29 & 25 & 152 & 73.5 \\
\hline \multicolumn{8}{|c|}{ Entidades privadas } \\
\hline Universidades privadas & 5 & 0 & 0 & 0 & 1 & 6 & 3 \\
\hline Asociaciones & 2 & 1 & 4 & 1 & 1 & 9 & 4 \\
\hline Notarías & 1 & 0 & 0 & 1 & 1 & 3 & 1 \\
\hline Empresas comerciales & 6 & 3 & 1 & 3 & 3 & 16 & 8 \\
\hline $\begin{array}{l}\text { Colegio de Abogados de } \\
\text { Lima }\end{array}$ & 2 & 0 & 0 & 0 & 0 & 2 & 1 \\
\hline Servicios de Agua & 1 & 1 & 0 & 0 & 2 & 4 & 2 \\
\hline Bancos & 3 & 0 & 1 & 0 & 2 & 6 & 3 \\
\hline Servicios de luz & 1 & 1 & 0 & 1 & 1 & 4 & 2 \\
\hline Mineras & 1 & 0 & 0 & 0 & 0 & 1 & 0.5 \\
\hline Servicios telefonía & 0 & 2 & 0 & 0 & 0 & 2 & 1 \\
\hline Arzobispado & 0 & 0 & 0 & 2 & 0 & 2 & 1 \\
\hline Total parcial & 22 & 8 & 7 & 8 & 11 & 55 & 26.5 \\
\hline Total general & 82 & 27 & 25 & 37 & 36 & 207 & 100 \\
\hline
\end{tabular}




\section{Materia de la demanda de Hábeas Data}

La materia en el ámbito judicial, es el derecho que se considera vulnerado y cuya protección o garantía se invoca a través de una demanda. En este caso, son dos derechos fundamentales, el acceso a la información y la autodeterminación informativa. Del análisis de las jurisprudencias, se ha determinado que casi la totalidad de las demandas están referidas al acceso a la información pública (92\%) y solo un mínimo $8 \%$ a la autodeterminación informativa. Esto se explica, toda vez que la ciudadanía aún no está informada, o carece de suficientes elementos de juicio que lo lleven a solicitar protección a sus datos personales, o ejercer su derecho a la autodeterminación informativa.

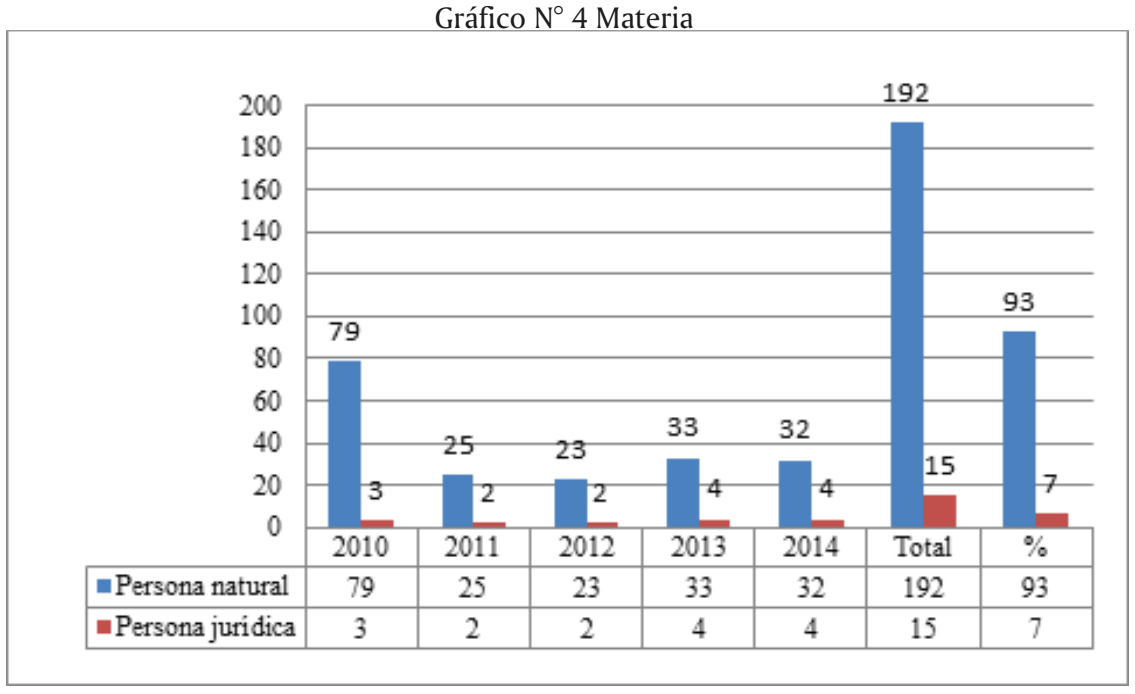

\section{Fallo del Tribunal Constitucional}

El fallo de un organismo autónomo como es el Tribunal Constitucional, comprende el contenido de las resoluciones que ponen fin al recurso de agravio constitucional, en este caso, de Hábeas Data. De todas las resoluciones analizadas, un poco menos de la mitad $(42 \%)$ fueron declaradas fundadas, lo cual significa que los fallos se ajustan a ley y se les da la razón a los demandantes. Sin embargo, si se compara las cifras con lo resuelto el año 2010, la mayoría de 
las demandas fueron declaradas fundadas, hecho que se redujo en los años posteriores. Mientras tanto, las resoluciones declaradas infundadas solo alcanzaron el $14 \%$. A su vez, casi la tercera parte (29\%) de las demandas fueron consideradas improcedentes, significa esto que presentaban errores de fondo que debían ser subsanadas. De estos datos se infiere que, las diferentes decisiones adoptadas en los fallos del TC, denotan que el recurso de agravio de Hábeas Data, requiere ser mejor entendido por los abogados y operadores del derecho, para así acudir al máximo organismo con actuados procesales que se ajusten a ley y evitar que las demandas sean declaradas improcedentes, revocadas o nulas, afectando los derechos de la ciudadanía.

Tabla $N^{\circ} 6$ Fallo del Tribunal

\begin{tabular}{|l|c|c|c|c|c|c|c|}
\hline Tipos de fallos & $\mathbf{2 0 1 0}$ & $\mathbf{2 0 1 1}$ & $\mathbf{2 0 1 2}$ & $\mathbf{2 0 1 3}$ & $\mathbf{2 0 1 4}$ & Total & $\mathbf{\%}$ \\
\hline Fundada & 40 & 10 & 7 & 18 & 12 & 87 & $42 \%$ \\
\hline Infundada & 7 & 4 & 7 & 3 & 8 & 29 & $14 \%$ \\
\hline Improcedente & 24 & 9 & 10 & 10 & 6 & 59 & $29 \%$ \\
\hline Revocar & 11 & 2 & 0 & 2 & 1 & 16 & $7 \%$ \\
\hline Nulo & 0 & 2 & 1 & 3 & 10 & 16 & $8 \%$ \\
\hline Total & 82 & 27 & 25 & 36 & 37 & 207 & $100 \%$ \\
\hline
\end{tabular}

\section{Conclusiones}

Primera.- El recurso de agravio constitucional de Hábeas Data, es una garantía contenida en la Constitución Política del Perú de 1993, protege dos derechos fundamentales, el acceso a la información y la autodeterminación informativa o protección de datos personales. Estos, son derechos humanos de tercera generación, cuyo principio es la solidaridad, en la que intervienen, las personas, el Estado y las empresas privadas. Esta garantía surge como respuesta al avance imparable de las nuevas tecnologías de la información y las comunicaciones, que, acopian, registran y procesan ingentes cantidades de datos personales, que si no son protegidos de acuerdo a los tratados internacionales y a las normas internas de cada país, pueden constituir un grave 
riesgo a la privacidad de los individuos.

Segundo.- Las demandas sobre acceso a la información y autodeterminación informativa resueltos por el Tribunal Constitucional del Perú durante los últimos cinco años (2010-2014), muestran que es muy limitado el ejercicio de estos dos derechos por parte de la población, si comparamos con los otros tipos de Garantía, como la Acción de Amparo y el Hábeas Corpus.

Tercero.- Se concluye que, la mayoría de las demandas fueron presentadas en la capital de la República, Lima Metropolitana (48\%). No obstante, un poco más de la mitad (52\%) accionaron en las otras ciudades del interior del país. Es explicable este hallazgo por cuanto la tercera parte de la población del país, 10 millones, se aglutina en la ciudad capital. Por otro lado, los demandantes que iniciaron la acción o reclamo judicial, en mayor porcentaje (93\%) fueron las personas naturales o lo que sociológicamente se les llama "ciudadanos de a pié", en tanto que las personas jurídicas, que pueden ser sociedades anónimas, de responsabilidad limitada o sociedades colectivas, solo alcanzaron un mínimo porcentaje de $7 \%$.

Cuarto.- Respecto al acceso a la información, casi la totalidad de las demandas (92\%) están referidas a la defensa de este derecho, a diferencia de las acciones judiciales sobre autodeterminación informativa, que solo representa un escaso $8 \%$. Este bajo porcentaje indica la poca efectividad de las normas que protegen este derecho, entre las causas que pueden ser explicadas están la falta de difusión a la ciudadanía, el desconocimiento de abogados, jueces y demás operadores del derecho respecto al procedimiento, así como, de los funcionarios del Estado.

\section{Referencias bibliográficas}

Agencia Española de Protección de Datos (2004). El derecho fundamental a la protección de datos: Guía para el ciudadano; ¿Qué es un dato personal? ¿Cuándo me piden los datos? ¿Cómo deben tratarse los datos? Recuperado de http://consumo-inc.gob.es/novedades/docs/ 
El Hábeas Data, protección al derecho a la información y a la autodeterminación informativa guiaProteccionDatos.pdf

Castilllo, L. (s.a.). El proceso de hábeas data (comentario al artículo 200 inciso 3). Gaceta-Congreso, Constitución comentada, t. II. p. 1008.

Constitución Política del Perú. http://spij.minjus.gob.pe/CLP/ contenidos.dll?f=templates $\& \mathrm{fn}=$ default-constitucion. htm $\& \mathrm{vid}=$ Ciclope:CLPdemo

Declaración Universal de los Derechos Humanos. http://www.un.org /es/documents/udhr/

Chanamé, R. (2003). Hábeas data y el derecho fundamental a la intimidad de la persona. Tesis para optar el grado de Magíster. Mención: Derecho Civily Comercial. Escuela de Post-Grado, Universidad Nacional Mayor de San Marcos. Facultad de Derecho y Ciencia Política. Escuela de Post-Grado. Lima, Perú.

Chirigoba, G. (2001). La acción de amparo y de hábeas data: garantías de los derechos constitucionales y su nueva realidad jurídica. Quito, AAJ/LLDIS.

Eguiguren, F. (1997). El Hábeas Data y su desarrollo en el Perú. Derecho, 51, 1997, pp. 291-310.

Estrada, A. (2004). El acceso a la información pública: un acercamiento doctrinal. INFOBIB. № 3, pp. 169-189.

Flores, P. (1987). Diccionario de términos jurídicos. V.3. Lima: Marsol Editores.

Flores, R. (2011). Amparo, Hábeas Corpus y Hábeas Data. Buenos Aires, Editorial B de F.

Ley $\mathrm{N}^{\circ}$ 29733. Ley de Protección de datos personales. (3 de julio de 2011). Recuperado de http://www.leyes.congreso.gob.pe/Documentos/ Leyes/29733.pdf

Marecos, A. (2011). La protección de datos personales como núcleo del derecho fundamental a la autodeterminación informativa. Una mirada desde el derecho español y europeo. En Corte Suprema de Justicia. División de Investigación, Legislación y Publicaciones. Protección de datos personales, pp.43-190. Asunción-Paraguay. 
Paraguay, Corte Suprema de Justicia - División de Investigación, Legislación y Publicaciones. (2010). Protección de Datos Personales. Asunción Paraguay.

Pauner, C. (2014). Derecho a la información. Valencia, Tirant Lo Blanch.

Pérez, A. (1990). Del hábeas corpus al hábeas Data. Informática y derecho, pp. 153-161. Recuperado de http://egov.ufsc.br/portal/sites/default/ files/6_16.pdf

Perú, Tribunal Constitucional. (2007). Sentencia del Tribunal Constitucional. Exp. $\mathrm{N}^{\circ}$ 01912-2007-HD/TC. Recuperado de http:// www. justiciaytransparencia.pe/sentencias /des_buscador. php?ULTIMA_SECCION $=283 \&$ SECCION_ID $=283 \&$ ELEMENT ID $=867 \&$ BUSQUEDA $=01912 \&$ ETIQUETAS $=$

Pulgar, N. (2006). El hábeas data en la protección de datos y el resguardo de la intimidad del trabajador. Maracaibo, Universidad de Zulia. Facultad de Ciencias Jurídicas y Políticas. + Informe final de trabajo de grado para optar el título de magíster scientiarium en derecho laboral y administración del trabajo.

Salazar, E. (2006). El Hábeas Data en el derecho comparado. Anuario, (29), pp.118-149.

Sánchez de Diego, M. (Coordinador) (2008). El derecho de acceso a la información pública. Madrid, Imprime CERSA.

Sosa, J. (2012). ¿Qué exactamente se protege a través del hábeas data? Alcances de la protección al derecho de acceso a la información pública en la jurisprudencia del Tribunal Constitucional. https:// sumaciudadana.wordpress.com/2012/03/071

Vásquez, M. (2012). El hábeas data en las redes sociales. Tesis de grado para optar el título de abogado. Universidad CES, Facultad de Derecho, Medellín. http://bdigital.ces.edu.co:8080/r epositorio/bitstream/10946/1281/2/Ha beas\%20data.pdf

Velezmoro, F. (2006). La protección de datos personales, la discusión sobre el 
bien jurídico tutelado y la posición del Tribunal Constitucional. Revista Actualidad Jurídica. Gaceta Jurídica, (150), pp-157-160.

Viega, M. y Baladán, F. (2014). Protección de datos personales en América Latina. Ampliando horizontes. En $34^{\circ}$ Conferencia Internacional de Autoridades de Protección de Datos y Privacidad. Privacidad y tecnología en equilibrio (pp. 172-180). Uruguay, Agencia para el Desarrollo de Gobierno de Gestión Electrónica y la Sociedad de la Información y el Conocimiento (AGESIC).

Viera, J. (1997). Fundamentos y características del Hábeas Data en Chile. Ius Et Praxis, 3(1), pp. 197-200.

Villegas, L. (2012). Protección de datos personales en América Latina: retención y tratamiento de datos personales en el mundo de Internet. En Hacia una internet libre de censura: propuestas para América Latina / compilado por Eduardo Andrés Bertoni. (pp.128-164). Buenos Aires: Universidad de Palermo - UP. http://www.palermo.edu/cele/pdf/ internet_libre_de_censura_libro.pdf

Zambrano, F. (2004). Constitución de la República de Venezuela. Caracas, Editorial Atenea. 
Anexo №1 Expedientes analizados sobre el Proceso de Hábeas Data (2010)

\begin{tabular}{|c|c|c|c|c|}
\hline \multicolumn{5}{|c|}{ Expedientes del año 2010| } \\
\hline $\begin{array}{l}\text { EXP. N. }{ }^{\circ} 00565-2010- \\
\text { PHD/TC }\end{array}$ & \begin{tabular}{|l} 
EXP. N. ${ }^{\circ} 01673-2010-$ \\
PHD/TC
\end{tabular} & $\begin{array}{l}\text { EXP. N. }{ }^{\circ} 05745-2009- \\
\text { PHD/TC }\end{array}$ & $\begin{array}{l}\text { EXP. N. }{ }^{\circ} 00890-2010- \\
\text { PHD/TC }\end{array}$ & $\begin{array}{l}\text { EXP. N. }{ }^{\circ} 00302-2010- \\
\text { PHD/TC }\end{array}$ \\
\hline $\begin{array}{l}\text { EXP. N. }{ }^{\circ} 00566-2010- \\
\text { PHD/TC }\end{array}$ & $\begin{array}{l}\text { EXP. N. }{ }^{\circ} 00746-2010- \\
\text { PHD/TC }\end{array}$ & $\begin{array}{l}\text { EXP. N. }{ }^{\circ} 05378-2009- \\
\text { PHD/TC }\end{array}$ & $\begin{array}{l}\text { EXP. N. }{ }^{\circ} 02814-2008- \\
\text { PHD/TC }\end{array}$ & $\begin{array}{l}\text { EXP. N. }{ }^{\circ} 01475-2010- \\
\text { PHD/TC }\end{array}$ \\
\hline $\begin{array}{l}\text { EXP. N. }{ }^{\circ} \text { 05486-2009- } \\
\text { PHD/TC }\end{array}$ & $\begin{array}{l}\text { EXP. N. }{ }^{\circ} 00849-2010- \\
\text { PHD/TC }\end{array}$ & $\begin{array}{l}\text { EXP. N. }{ }^{\circ} 04734-2009- \\
\text { PHD/TC }\end{array}$ & $\begin{array}{l}\text { EXP. N. }{ }^{\circ} 02874-2009- \\
\text { PHD/TC }\end{array}$ & $\begin{array}{l}\text { EXP. N. } .^{\circ} 04308-2009- \\
\text { PHD/TC }\end{array}$ \\
\hline $\begin{array}{l}\text { EXP. N. }{ }^{\circ} 06070-2009- \\
\text { PHD/TC }\end{array}$ & $\begin{array}{l}\text { EXP. N. }{ }^{\circ} 05400-2009- \\
\text { PHD/TC }\end{array}$ & $\begin{array}{l}\text { EXP. N. }{ }^{\circ} 06069-2009- \\
\text { PHD/TC }\end{array}$ & $\begin{array}{l}\text { EXP. N. }{ }^{\circ} 01726-2010- \\
\text { PHD/TC }\end{array}$ & $\begin{array}{l}\text { EXP. N. }{ }^{\circ} 02355-2010- \\
\text { PHD/TC }\end{array}$ \\
\hline EXP. № 6238 -2008-PHD & $\begin{array}{l}\text { EXP. N. }{ }^{\circ} 04283-2009- \\
\text { PHD/TC }\end{array}$ & $\begin{array}{l}\text { EXP. N. }{ }^{\circ} 00887-2010- \\
\text { PHD/TC }\end{array}$ & $\begin{array}{l}\text { EXP. N. }{ }^{\circ} 05319-2009- \\
\text { PHD/TC }\end{array}$ & $\begin{array}{l}\text { EXP. N. }{ }^{\circ} 00300-2010- \\
\text { PHD/TC }\end{array}$ \\
\hline $\begin{array}{l}\text { EXP. N. }{ }^{\circ} 0202-2009- \\
\text { PHD/TC }\end{array}$ & $\begin{array}{l}\text { EXP. N. }{ }^{\circ} 01712-2010- \\
\text { PHD/TC }\end{array}$ & $\begin{array}{l}\text { EXP. N. }{ }^{\circ} 05898-2009- \\
\text { PHD/TC }\end{array}$ & $\begin{array}{l}\text { EXP. N. }{ }^{\circ} 02481-2010- \\
\text { PHD/TC }\end{array}$ & $\begin{array}{l}\text { EXP. N. }{ }^{\circ} 00051-2010- \\
\text { PHD/TC }\end{array}$ \\
\hline $\begin{array}{l}\text { EXP. N. }{ }^{\circ} 02727-2010- \\
\text { PHD/TC }\end{array}$ & $\begin{array}{l}\text { EXP. N. }{ }^{\circ} 04012-2009- \\
\text { PHD/TC }\end{array}$ & $\begin{array}{l}\text { EXP. N. }{ }^{\circ} 02892-2009- \\
\text { PHD/TC }\end{array}$ & $\begin{array}{l}\text { EXP. N. }{ }^{\circ} 05102-2009- \\
\text { PHD/TC }\end{array}$ & $\begin{array}{l}\text { EXP. N. }{ }^{\circ} 00204-2008- \\
\text { PHD/TC }\end{array}$ \\
\hline $\begin{array}{l}\text { EXP. N. }{ }^{\circ} 01454-2010- \\
\text { PHD/TC }\end{array}$ & $\begin{array}{l}\text { EXP. N. }{ }^{\circ} 01266-2010- \\
\text { PHD/TC }\end{array}$ & $\begin{array}{l}\text { EXP. N. }{ }^{\circ} 05982-2009- \\
\text { PHD/TC }\end{array}$ & EXP. N. ${ }^{\circ} 2681-2009-\mathrm{HD} / \mathrm{TC}$ & $\begin{array}{l}\text { EXP. N. }{ }^{\circ} 03221-2010- \\
\text { PHD/TC }\end{array}$ \\
\hline $\begin{array}{l}\text { EXP.N. }{ }^{\circ} 05718-2009- \\
\text { HD/TD }\end{array}$ & $\begin{array}{l}\text { EXP. N. }{ }^{\circ} 03156-2009- \\
\text { PHD/TC }\end{array}$ & $\begin{array}{l}\text { EXP. N. }{ }^{\circ} 04645-2009- \\
\text { PHD/TC }\end{array}$ & $\begin{array}{l}\text { EXP. N. }{ }^{\circ} 04073-2009- \\
\text { PHD/TC }\end{array}$ & $\begin{array}{l}\text { EXP. N. }{ }^{\circ} 01141-2010- \\
\text { PHD/TC }\end{array}$ \\
\hline $\begin{array}{l}\text { EXP. N. }{ }^{\circ} 00572-2010- \\
\text { PHD/TC }\end{array}$ & $\begin{array}{l}\text { EXP. N. }{ }^{\circ} 04145-2009- \\
\text { PHD/TC }\end{array}$ & $\begin{array}{l}\text { EXP. N. }{ }^{\circ} 04886-2009- \\
\text { PHD/TC }\end{array}$ & $\begin{array}{l}\text { EXP. N. }{ }^{\circ} 06109-2009- \\
\text { PHD/TC }\end{array}$ & $\begin{array}{l}\text { EXP. N. }{ }^{\circ} 03693-2010- \\
\text { PHD/TC }\end{array}$ \\
\hline $\begin{array}{l}\text { EXP. N. }{ }^{\circ} 03803-2008- \\
\text { PHD/TC }\end{array}$ & $\begin{array}{l}\text { EXP N. }{ }^{\circ} 04905-2008- \\
\text { PHD/TC }\end{array}$ & $\begin{array}{l}\text { EXP. N. }{ }^{\circ} 01864-2010- \\
\text { PHD/TC }\end{array}$ & EXP. N. ${ }^{\circ} 0588-2010-\mathrm{PHD} / \mathrm{TC}$ & $\begin{array}{l}\text { EXP. N. } .^{\circ} 00879-2008- \\
\text { PHD/T }\end{array}$ \\
\hline $\begin{array}{l}\text { EXP N. }{ }^{\circ} \text { 03069-2009- } \\
\text { PHD/TC }\end{array}$ & $\begin{array}{l}\text { EXP. N. }{ }^{\circ} 04368-2009- \\
\text { PHD/TC }\end{array}$ & $\begin{array}{l}\text { EXP. N. }{ }^{\circ} 06040-2009- \\
\text { PHD/TC }\end{array}$ & EXP. N No $^{\circ} 0435-2010-\mathrm{PHD} / \mathrm{TC}$ & $\begin{array}{l}\text { EXP. N. }{ }^{\circ} 01836-2010- \\
\text { PHD/TC }\end{array}$ \\
\hline $\begin{array}{l}\text { EXP. N. }{ }^{\circ} 03976-2009- \\
\text { PHD/TC }\end{array}$ & $\begin{array}{l}\text { EXP. N. }{ }^{\circ} 03019-2010- \\
\text { PHD/TC }\end{array}$ & $\begin{array}{l}\text { EXP. N. }{ }^{\circ} \text { 04884-2009- } \\
\text { PHD/TC }\end{array}$ & $\begin{array}{l}\text { EXP. N. }{ }^{\circ} 01269-2010- \\
\text { PHD/TC }\end{array}$ & $\begin{array}{l}\text { EXP. N. } .^{\circ} 02113-2008- \\
\text { PHD/TC }\end{array}$ \\
\hline $\begin{array}{l}\text { EXP. N. }{ }^{\circ} 05406-2009- \\
\text { PHD/TC }\end{array}$ & $\begin{array}{l}\text { EXP. N.o } 03802-2008- \\
\text { PHD/TC }\end{array}$ & $\begin{array}{l}\text { EXP. N. }{ }^{\circ} \text { 05777-2008- } \\
\text { PHD/TC }\end{array}$ & $\begin{array}{l}\text { EXP. N. } 02512-2009- \\
\text { PHD/TC }\end{array}$ & $\begin{array}{l}\text { EXP. N. } .^{\circ} 00854-2010- \\
\text { PHD/TC }\end{array}$ \\
\hline $\begin{array}{l}\text { EXP. N. }{ }^{\circ} 05209-2009- \\
\text { PHD/TC }\end{array}$ & $\begin{array}{l}\text { EXP. N. }{ }^{\circ} 05589-2009- \\
\text { PHD/TC }\end{array}$ & $\begin{array}{l}\text { EXP. N. }{ }^{\circ} 01347-2010- \\
\text { PHD/TC }\end{array}$ & EXP. N. ${ }^{\circ} 0554-2010-\mathrm{PHD} / \mathrm{TC}$ & $\begin{array}{l}\text { EXP. N. }{ }^{\circ} 01581-2010- \\
\text { PHD/TC }\end{array}$ \\
\hline $\begin{array}{l}\text { EXP. N. }{ }^{0} 04146-2009- \\
\text { PHD/TC }\end{array}$ & $\begin{array}{l}\text { EXP. N. }{ }^{\circ} 01681-2010- \\
\text { PHD/TC }\end{array}$ & $\begin{array}{l}\text { EXP. N. }{ }^{\circ} 05254-2009- \\
\text { PHD/TC }\end{array}$ & $\begin{array}{l}\text { EXP. N. }{ }^{\circ} 00750-2010- \\
\text { PHD/TC }\end{array}$ & $\begin{array}{l}\text { EXP. N. }{ }^{\circ} 03652-2009- \\
\text { PHD/TC }\end{array}$ \\
\hline $\begin{array}{ll}\text { EXP. N.。 02719 } & -2007- \\
\text { PHD/TC } & \end{array}$ & $\begin{array}{l}\text { EXP. N.o. } 02845-2008- \\
\text { HD/T }\end{array}$ & & 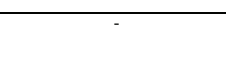 & 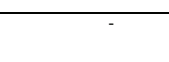 \\
\hline
\end{tabular}

Anexo $N^{\circ} 2$ Expedientes analizados sobre el Proceso de Hábeas Data (2011-2014)

\begin{tabular}{|c|c|c|c|}
\hline 2011 & 2012 & 2013 & 2014 \\
\hline EXP. N. ${ }^{\circ} 04175-2011-\mathrm{HD} / \mathrm{TC}$ & EXP. N. ${ }^{\circ} 00300-2012-\mathrm{PHD} / \mathrm{TC}$ & EXP. N $.^{\circ} 03426-2012-\mathrm{PHD} / \mathrm{TC}$ & EXP. $\mathrm{N}^{\circ} 03470-2013-\mathrm{PHD} / \mathrm{TC}$ \\
\hline EXP. N. ${ }^{\circ} 00776-2010-\mathrm{PHD} / \mathrm{TC}$ & EXP. N. ${ }^{\circ} 02627-2011-\mathrm{PHD} / \mathrm{TC}$ & EXP. N. ${ }^{\circ} 04141$-2012-PHD/TC & EXP. N. ${ }^{\circ} 04203-2012-\mathrm{PHD} / \mathrm{TC}$ \\
\hline EXP. N ${ }^{\circ} 03986-2009-\mathrm{PHD} / \mathrm{TC}$ & EXP. N. $.^{\circ} 04706-2011-\mathrm{PHD} / \mathrm{TC}$ & EXP. N. $.^{\circ} 04387-2011-P H D / T C$ & EXP. N. ${ }^{\circ} 03672-2013-\mathrm{PHD} / \mathrm{TC}$ \\
\hline EXP. N. ${ }^{\circ} 01542-2009-\mathrm{PHD} / \mathrm{TC}$ & EXP. N. ${ }^{\circ} 00841-2012-\mathrm{PHD} / \mathrm{TC}$ & EXP. N. ${ }^{\circ} 00441$-2012-PHD/TC & EXP. N. ${ }^{\circ} 02992-2013-\mathrm{PHD} / \mathrm{TC}$ \\
\hline EXP. No $04602-2008-\mathrm{PHD} / \mathrm{TC}$ & EXP. N. ${ }^{\circ} 04042-2011-\mathrm{PHD} / \mathrm{TC}$ & EXP. N ${ }^{\circ}$ 03207-2012-PHD/TC & EXP. N. ${ }^{\circ} 06227-2013-\mathrm{PHD} / \mathrm{TC}$ \\
\hline EXP. N. ${ }^{\circ} 00147-2011-\mathrm{PHD} / \mathrm{TC}$ & EXP. N. ${ }^{\circ} 02341$-2012-PHD/TC & EXP. N. ${ }^{\circ} 01506-2012-\mathrm{PHD} / \mathrm{TC}$ & EXP. N. ${ }^{\circ} 03855-2013-\mathrm{PHD} / \mathrm{TC}$ \\
\hline EXP. N. $.^{\circ} 01303-2011-\mathrm{PHD} / \mathrm{TC}$ & EXP. N. ${ }^{\circ} 00598-2012-\mathrm{PHD} / \mathrm{TC}$ & EXP. N. ${ }^{\circ} 01286-2012-\mathrm{PHD} / \mathrm{TC}$ & EXP. N. ${ }^{\circ} 00831-2010-\mathrm{PHD} / \mathrm{TC}$ \\
\hline EXP. N. ${ }^{\circ} 00297-2011-\mathrm{PHD} / \mathrm{TC}$ & EXP. N. ${ }^{\circ} 01492-2012-\mathrm{PHD} / \mathrm{TC}$ & EXP. N. ${ }^{\circ} 01759-2013-\mathrm{PHD} / \mathrm{TC}$ & EXP. $\mathrm{N}^{\circ} 04846-2013-\mathrm{PHD} / \mathrm{TC}$ \\
\hline
\end{tabular}


El Hábeas Data, protección al derecho a la información y a la autodeterminación informativa

\begin{tabular}{|c|c|c|c|}
\hline EXP. N. ${ }^{\circ} 04227-2009-\mathrm{PHD} / \mathrm{TC}$ & EXP. N. ${ }^{\circ} 01388-2012-\mathrm{PHD} / \mathrm{TC}$ & EXP. N. ${ }^{\circ} 01682-2013-\mathrm{PHD} / \mathrm{TC}$ & EXP. N. ${ }^{\circ} 03859-2012-\mathrm{PHD} / \mathrm{TC}$ \\
\hline EXP. N. ${ }^{\circ} 05624-2009-\mathrm{PHD} / \mathrm{TC}$ & EXP. N. $.^{\circ} 01133-2012-\mathrm{PHD} / \mathrm{TC}$ & EXP. N. ${ }^{\circ} 01685-2013-\mathrm{PHD} / \mathrm{TC}$ & EXP. N. ${ }^{\circ} 01482-2013-\mathrm{PHD} / \mathrm{TC}$ \\
\hline EXP. N. ${ }^{\circ} 00097-2011-\mathrm{PHD} / \mathrm{TC}$ & EXP. N. ${ }^{\circ} 05112-2011-\mathrm{PHD} / \mathrm{TC}$ & EXP. No $01317-2013-\mathrm{PHD} / \mathrm{TC}$ & EXP. $\mathrm{N}^{\circ} 02512-2013-\mathrm{PHD} / \mathrm{TC}$ \\
\hline EXP. N. ${ }^{\circ}$ 02987-2011-PHD/TC & EXP. N..$^{\circ}$ 05104-2011-PHD/TC & EXP. No $01359-2013-\mathrm{PHD} / \mathrm{TC}$ & EXP. N. ${ }^{\circ} 08217-2013-\mathrm{PHD} / \mathrm{TC}$ \\
\hline EXP. N. ${ }^{\circ} 03864-2010-\mathrm{PHD} / \mathrm{TC}$ & EXP. N. ${ }^{\circ} 04739-2011-\mathrm{PHD} / \mathrm{TC}$ & EXP. N. ${ }^{\circ} 04710-2011-\mathrm{PHD} / \mathrm{TC}$ & EXP. N. ${ }^{\circ} 02830-2013-\mathrm{PHD} / \mathrm{TC}$ \\
\hline EXP. N. ${ }^{\circ} 0831-2010-\mathrm{PHD} / \mathrm{TC}$ & EXP. N. $.^{\circ} 04627-2011-\mathrm{PHD} / \mathrm{TC}$ & EXP. N ${ }^{\circ} 00992-2013-\mathrm{PHD} / \mathrm{TC}$ & EXP. N. ${ }^{\circ} 02332-2013-\mathrm{PHD} / \mathrm{TC}$ \\
\hline EXP. N. ${ }^{\circ}$ 02139-2011-PHD/TC & EXP. N. ${ }^{\circ} 04425-2009-\mathrm{PHD} / \mathrm{TC}$ & EXP. N. ${ }^{\circ} 03773-2012-\mathrm{PHD} / \mathrm{TC}$ & EXP. N. ${ }^{\circ} 01475-2013-\mathrm{PHD} / \mathrm{TC}$ \\
\hline EXP. N. ${ }^{\circ} 03911-2011-\mathrm{PHD} / \mathrm{TC}$ & EXP. N. ${ }^{\circ} 00767-2012-\mathrm{PHD} / \mathrm{TC}$ & EXP. N. ${ }^{\circ} 01812-2012-\mathrm{PHD} / \mathrm{TC}$ & EXP. N. ${ }^{\circ} 02292-2012-\mathrm{PHD} / \mathrm{TC}$ \\
\hline EXP. N. ${ }^{\circ} 01252-2011-\mathrm{PHD} / \mathrm{TC}$ & EXP. N. ${ }^{\circ} 00641$-2012-PHD/TC & EXP. N. ${ }^{\circ} 04764-2012-\mathrm{PHD} / \mathrm{TC}$ & EXP. $\mathrm{N}^{\circ} 04759-2012-\mathrm{PHD} / \mathrm{TC}$ \\
\hline EXP. N. ${ }^{\circ} 02655-2011-\mathrm{PHD} / \mathrm{TC}$ & EXP. N. ${ }^{\circ} 04910-2011-\mathrm{PHD} / \mathrm{TC}$ & EXP. N. ${ }^{\circ} 00541-2013-\mathrm{PHD} / \mathrm{TC}$ & EXP. N $.^{\circ} 04611-2013-\mathrm{PHD} / \mathrm{TC}$ \\
\hline EXP. N. ${ }^{\circ} 01352-2011-\mathrm{PHD} / \mathrm{TC}$ & EXP. N. ${ }^{\circ} 00971-2012-\mathrm{PHD} / \mathrm{TC}$ & EXP. N. ${ }^{\circ} 04861-2012-\mathrm{PHD} / \mathrm{TC}$ & EXP. N. ${ }^{\circ} 01719-2013-\mathrm{PHD} / \mathrm{TC}$ \\
\hline EXP. N. ${ }^{\circ} 01097-2011-\mathrm{PHD} / \mathrm{TC}$ & EXP. N. ${ }^{\circ} 03598-2011-\mathrm{PHD} / \mathrm{TC}$ & EXP. N. ${ }^{\circ} 00693-2012-\mathrm{PHD} / \mathrm{TC}$ & EXP. N $.^{\circ} 04865-2013-\mathrm{PHD} / \mathrm{TC}$ \\
\hline EXP. N. ${ }^{\circ} 02838-2009-\mathrm{PHD} / \mathrm{TC}$ & EXP. N. $.^{\circ} 00530-2012-\mathrm{PHD} / \mathrm{TC}$ & EXP. N. ${ }^{\circ} 03035-2012-\mathrm{PHD} / \mathrm{TC}$ & EXP. N $.^{\circ} 03993-2013-\mathrm{PHD} / \mathrm{TC}$ \\
\hline EXP. N. ${ }^{\circ} 03733-2011-\mathrm{PHD} / \mathrm{TC}$ & EXP. N. ${ }^{\circ} 00183-2012-\mathrm{PHD} / \mathrm{TC}$ & EXP. N. ${ }^{\circ} 05517-2011-\mathrm{PHD} / \mathrm{TC}$ & EXP. $\mathrm{N}^{\circ} 05660-2013-\mathrm{PHD} / \mathrm{TC}$ \\
\hline EXP. N. ${ }^{\circ} 02661-2011-\mathrm{PHD} / \mathrm{TC}$ & EXP. N. ${ }^{\circ} 00987-2012-\mathrm{PHD} / \mathrm{TC}$ & EXP. N. ${ }^{\circ} 03200-2011-\mathrm{PHD} / \mathrm{TC}$ & EXP. N. ${ }^{\circ} 01384-2013-\mathrm{PHD} / \mathrm{TC}$ \\
\hline EXP. N. ${ }^{\circ}$ 03839-2011-PHD/TC & EXP. N. $.^{\circ} 00964-2011-\mathrm{PHD} / \mathrm{TC}$ & EXP. N. ${ }^{\circ} 01837-2012-\mathrm{PHD} / \mathrm{TC}$ & EXP. N. ${ }^{\circ} 02376-2013-\mathrm{PHD} / \mathrm{TC}$ \\
\hline EXP. N. ${ }^{\circ} 01143-2011-\mathrm{PHD} / \mathrm{TC}$ & EXP. N. ${ }^{\circ} 03943-2011-\mathrm{PHD} / \mathrm{TC}$ & EXP. N. ${ }^{\circ} 03406-2012-\mathrm{PHD} / \mathrm{TC}$ & EXP. N. $.^{\circ} 00168-2010-\mathrm{PHD} / \mathrm{TC}$ \\
\hline EXP. N. ${ }^{\circ} 01641-2011-\mathrm{PHD} / \mathrm{TC}$ & - & EXP. N. ${ }^{\circ} 01636-2013-\mathrm{PHD} / \mathrm{TC}$ & EXP. N. ${ }^{\circ} 02994-2013-\mathrm{PHD} / \mathrm{TC}$ \\
\hline EXP. N. ${ }^{\circ} 02945-2011-\mathrm{PHD} / \mathrm{TC}$ & - & EXP. N. ${ }^{\circ} 04392-2012-\mathrm{PHD} / \mathrm{TC}$ & EXP. N. ${ }^{\circ} 00506-2013-\mathrm{PHD} / \mathrm{TC}$ \\
\hline- & - & EXP. N. ${ }^{\circ} 00575-2013-\mathrm{PHD} / \mathrm{TC}$ & EXP. N. ${ }^{\circ} 01052-2013-\mathrm{PHD} / \mathrm{TC}$ \\
\hline - & - & EXP. N. ${ }^{\circ} 01372-2012-\mathrm{PHD} / \mathrm{TC}$ & EXP. N. ${ }^{\circ} 00937-2013-\mathrm{PHD} / \mathrm{TC}$ \\
\hline- & - & EXP. N. ${ }^{\circ} 03769-2012-\mathrm{PHD} / \mathrm{TC}$ & EXP. N. ${ }^{\circ} 01804-2013-\mathrm{PHD} / \mathrm{TC}$ \\
\hline- & - & EXP. N. ${ }^{\circ} 00313-2013-\mathrm{PHD} / \mathrm{TC}$ & EXP. N. ${ }^{\circ} 04396-2013-\mathrm{PHD} / \mathrm{TC}$ \\
\hline & - & EXP. N. ${ }^{\circ} 03314-2012-\mathrm{PHD} / \mathrm{TC}$ & EXP. N. ${ }^{\circ} 00506-2013-\mathrm{PHD} / \mathrm{TC}$ \\
\hline - & - & EXP. N. ${ }^{\circ} 03393-2012-\mathrm{PHD} / \mathrm{TC}$ & EXP. N. ${ }^{\circ} 03351-2013-\mathrm{PHD} / \mathrm{TC}$ \\
\hline - & & EXP. N. ${ }^{\circ} 02838-2012-\mathrm{PHD} / \mathrm{TC}$ & EXP. N. ${ }^{\circ} 02818-2013-\mathrm{PHD} / \mathrm{TC}$ \\
\hline
\end{tabular}

